\title{
Representation of Sexuality on Television: Values and Attitudes of Young Malaysian
}

\author{
Fauziah Ahmad ${ }^{1}$, Latiffah Pawanteh ${ }^{1}$, Samsudin A. Rahim $^{1}$, Mohd Helmi Abd. Rahim ${ }^{1}$ \& Rusyda Helma Mohd ${ }^{1}$ \\ 1 School of Media and Communication Studies, Faculty of Social Sciences and Humanities, Universiti \\ Kebangsaan Malaysia, Bangi, Malaysia \\ Correspondence: Fauziah Ahmad, School of Media and Communication Studies, Faculty of Social Sciences and \\ Humanities, Universiti Kebangsaan Malaysia, 43600 Bangi, Selangor, Malaysia. Tel: 60-3-8921-4387, \\ 60-3-8921-4277. E-mail: zuhair@ukm.my
}

Received: October 28, $2011 \quad$ Accepted: May 9, $2012 \quad$ Published: June 1, 2012

doi:10.5539/ass.v8n7p77 URL: http://dx.doi.org/10.5539/ass.v8n7p77

This project is funded by Universiti Kebangsaan Malaysia under the research code: UKM-GUP-TKS-08-11-287

\begin{abstract}
Technological changes are expanding rapidly which in turn has had an immense impact on the behaviour of young people, the massive users of technology. The mass media provides a diverse source of cultural opinions and standards to young people as well as differing examples of identity. Young people would be able to look at these and decide which they found most favourable and also to what they aspire to be. They use media and the cultural insights provided by them to see both who they might be and how they should behave. This paper explores the consequences of the advent of global media specifically via television in the lives of young people in Malaysia and their values and attitude towards issues of sexuality. Results revealed that the meanings that are gathered from the media are open to reshaping and refashioning to suit their individual needs, whether to accept or deny.
\end{abstract}

Keywords: global media, young people, values, attitudes, sexuality and television

\section{Introduction}

We live today in an ever-increasingly fast changing and a superior interconnected world. It is a global society of communicative interactions and responses that stimulates profound cultural transformations and realignments. It is a society epitomised by the advent of globalisation paralleled by the arrival of superb cutting-edge technologies. In essence, the changing global media landscape and the arrival of a powerful global media-driven culture are shaping the socialisation processes, values, and beliefs of young people. At the same time it is influencing young people's decisions, in areas such as educational choice, employment, leisure, and life in general. Global media and technology have revolutionized the way young people are accessing information and entertainment. It has experienced a great deal of technological expansion during the last century, which in turn has had an immense impact on the behaviour of young people.

New technologies offer a culture of information, pleasure and relative autonomy, all of which are of particular appeal to society's youth. This has implications not only for young people themselves but also for their relationships within the family and between generations. The advent of globalization has meant, for many young people, the sphere of experience has become global and local at once. Young people are often among the first to take advantage of their introduction. Subsequently, the challenge is to give culturally valid meaning to the use of new technologies. While mass media technology is generally used for profit and power, the technology is also blamed for eroding cultural and moral values. As such, sexual knowledge, values, and attitudes of young people, the largest consumer of media are at stake.

The year 2010 sees Malaysia focusing to celebrate on innovation and creativity. Fifty-three years after its independence, it is a well advanced country with the 1Malaysia concept. It is designing to re-orient itself, gearing for a new direction towards greater unity and success. It speaks of harmonious living among diverse cultural groups, constant economic growth, political stability, elevating living standards among the population all grounded within a unique potpourri of living patterns that is steeped in tradition but yet able to accommodate and 
withstand the onslaught of global cultural ways without losing her local cultural balance (Nobaya Ahmad \& Samsudin A. Rahim 2008). Nevertheless, somehow the advent and advancement of global media has brought new challenges and changes to the social and cultural milieu of young people. The mass media and popular culture are the medium for affecting change on a large scale, and it has succeeded to help shape messages that reach millions of young people.

\section{Literature Review}

\subsection{Representation of Sexuality, Television and Young People}

In the world of communication, global media stands out not only to disseminate information, they also shape and influence people's opinion. Young people' status quo and their development should be the focus of any nation's agenda. The National Youth Development Policy of Malaysia defined youth as people aged between 15 and 40 years. But the main focus of young people's development program and activities in the country is very much focused on young people aged 18 to 25 years. The United Nation defines youth or young people as persons aged 15 to 24 years $^{2}$. The country's population has more than tripled over the last four decades and, in 2002, was 24.5 million. Young people (15-24 years of age) make up a fifth of the population ${ }^{1}$.

They have the potential to change the life trends of a society and nation. Global media has made the world smaller, human becoming more advanced but moral values are eroding through intelligence and technology. Human have become robust with global media. Sexual images and pornography which is censored on television in Malaysia is available and can be downloaded on the cell phone via short messaging system and young adult can view it anytime. Dissemination of information and knowledge is spreading rapidly through a borderless world.

Current media portrayals offer the population especially young people with various media alternatives in their daily media and information curiosity. Globalisation has brought many challenges and the media, both newspapers and electronic, need to realise that the population especially youth still want their news and information but their expectations have changed in recent years due to globalisation and the global media. No doubt while ICT has the potential to empower youth and improve their lives in many respects, it has also created greater disparities among society. The increase use of the internet has created more knowledgeable and actively seeking information young people. However, there is fear that their inquisitive instincts have blurred the lines between good and bad values. Easy access to technology is challenged with contemporary problems such as exposure to violence, pornography and materials that are confined to the domains of adults.

Youths are easily influenced by what they see as they are still at the fragile age of $18-24$. The media is often seen powerful shapers of their identity because media remain popular and pervasive in the lives of most global youth. Young people today are highly mediated with a wide provision and instant access to the media such as the internet. Global media lifestyles have pervaded youth culture today as they localise global media influences and globalise local lifestyles. They expect to get information through channels that they are comfortable with and they rely on the mass media as sources of information about sexual relationships though much of what they see and hear is somehow incorrect, incomplete, misleading, or misguided and depicts irresponsible behavior as exciting and even rewarding. Research conducted by Shanti Balraj-Ambigapathy (2000) revealed that television media forms a major part in the development and growth of children. Television, unlike all other media reaches children a very early age with a great intensity and these children will soon become young people. The children's opinions of what they watched are very important because the impression of what they watch can last for a long time.

According to Nobaya Ahmad and Samsudin A. Rahim (2008), youth generally comprises the most media and technology literate sector of their societies. With the increase in internet usage youth culture today is highly mediated. The internet is able to provide youth all over the world with instant access with a wide variety of diverse cultural forms and styles. No doubt that it is the radios and televisions that remain popular and pervasive media in the lives of most global youth, the internet is often displacing them as a primary influence. There is a high concentration of media activities among young people today and therefore, one could contribute their construction of realities as partly and directly influenced by various media images. The media has always been seen as powerful shapers and causes of homogenisation between cultures.

When considering how much time adolescents are in contact with the popular media, be it television, magazines, advertising, music or the Internet, it is clear to see that it is bound to have a marked effect on an individual's behaviour and lifestyle. This is especially the case when the medium itself is concerned with the lifestyle of young people. Latiffah and Samsudin (2000) asserts that media penetration means that young people are spending relatively more time with communication medium and it can be assumed that this leads to a higher exposure of and 
to its contents. They are concerned with the media content as it is the integral component of young adult's socialization with media. From media content, they will develop the social constructs about themselves and the environment.

A study by Malaysian Institute for Youth Development (2008) as cited from Latiffah and Samsudin (2008) points out that more than $90 \%$ of young people have access to terrestrial television, radio and newspaper, $75 \%$ for satellite television and $86 \%$ of young people have access to computer at home or cybercafé. They observed that young people spent considerable number of hours sitting in front of one media or the other. Thus the average time spent with various media range from 13 to 19 hours per week. The main preoccupation of young people seems to focus on radio and television. While the television may be a good thing for us parents, the fact is that the results of numerous studies conducted over the past decade show that spending a long time watching television is not good for children. Daily, children have at our disposal an enormous array of possible images of violence, obscenity and sexuality. It is quite common for children when they come home from school to switch on the television and watch the programmes especially designed for them, copy the behaviour portrayed on screen and somehow use it, constructing their behaviour from aspects of the characters in the drama (Katherine Miller 2005).

Kamal Sohaimi Fadzil \& Ng Chirp Jenn (2006) said that the adolescent's age is an age of transition before taking the responsibility to be an adult. This is the period where they seek to establish their personal identity and attempt to find meaning in their lives. They look within themselves to examine thoughts and feelings, and to reason about them. This leads many young people to seek answers to questions about sexuality. Conventional religious beliefs and participation in organized religious practices demonstrate aspects of spirituality. However, adolescent spirituality is often demonstrated in a more fundamental way through the adolescent's search for meaning in life's daily experiences (Dacey \& Kenny 1997).

Sexuality is an expression of identity through gender (male and female). It is also a personal and private feeling that involves understanding of one's own sexual responses and emotions. These feelings include personal values and beliefs that interact with general concept of sex, for example, love and sexual orientation. In Malaysia, issues of sexuality are seldom discussed openly and directly, hence they are often shrouded in customary prescriptions and practices. Discussions on sexuality have largely remained a taboo subject. Due to the sensitivity of these issues, young people receive inadequate education and information on sexuality. They are not free to discuss matters pertaining to sexuality with parents as it is always thought to be a shameful subject. Similarly parents cannot easily communicate their thoughts about sex with their children as they themselves were taught to remain silent about the subject. In actual fact, the basic moral attitudes should be told out loud so that young people can learn to confront and deal with real world issues.

Human sexuality is not simply imposed by instinct or stereotypical conducts, as it happens in animals, it is influenced both by superior mental activity and by social, cultural and educational but characteristics of those places where the subjects grow up and their personality develops. Human sexuality can also be understood as part of the social life of humans, governed by implied rules of behavior. Sexuality is often defined simply in terms of sex, but sexuality encompasses many different aspects of our lives beyond just sex alone. Sexuality is determined in part by our genetics and in part by the social expression of our underlining heredity and interaction with others. Young people' problem related to behavior, lifestyle or sexuality are due to changing familial structures resulting from young men and women from rural to urban areas, the exposure of mass media and with the growth of communication technology. Many people's concern about the exposure of young people to sex in the media has two main aspects. First, there is a worry that very young children may be upset by seeing explicit sexual scenes that they lack the maturity to interpret. Second, exposure to media content that places emphasis on sexual themes among teenagers is believed to encourage early onset of sexual behavior and contributes, in turn, to the growth in unwanted teenage pregnancies and sexually transmitted diseases.

In many instances, the media whether print or electronic has been criticised for the negative influence on the morality and behaviour of young people. Media permeates everything that we do. Consequently, the imagery in the media is bound to infiltrate into young people's lives. This is especially the case when young people are in the process of constructing their identities or in establishing a behavior characteristic. Through television, magazines, advertising, music and the Internet young people have a great deal of resources available to them in order for them to choose how they would like to carry themselves. The portrayals of young adult roles in local news and television programmes pave way for young people in reality world to be easily influenced. Young adult is always on the look for signs and opportunities to lead a contemporary lifestyle. Media seems to determine their fashion, hairstyle, conversation and engagement with friends. 


\subsection{Values and Attitudes of Young People}

Humans learn in many ways and one of the most important alternative routes to learning is through watching others who are demonstrating 'behaviours'. Researchers posited that if humans were motivated to learn a particular behavior, they would be able to learn by observing models. Learning can occur through the observation of these models. Social cognitive theory deals with the concept of learning through observation and imitation. People are learners who could think about the content of the media and whose thinking could then make a difference in the acquisition of new values, attitudes and behaviours.

Attitude is defined as negative or positive evaluations of thought or object. The cognitive component of attitude is made up of the beliefs people hold about certain things. The affective component comprises the emotional feelings stimulated by an object of thought. And finally the behavioural component of an attitude consists of predispositions to act in a specific way towards something (Weiten 2001). Values shape an individual's basic attitude to life carrying a set of assumptions about the way life should be lived. They govern an individual's behavior and choices. Individual's morals may derive from society and government, religion or self. Too often young people today are most influenced by what they see and hear on television or on the street which could influence their attitude and identity and subsequently, values.

Values are the foundations for healthy and safe sexual and social relationships in adult life. This includes respect and responsibility acquired and developed in childhood and at puberty. For these values to take root, they need reinforcement. Young people have to be equipped with the necessary knowledge and skills to make responsible choices in their social and sexual lives. An individual's sexual development is a complex process that involves physical, psychological, social, and cultural dimensions which has a strong link to the development of one's individual identity. Many parents are often reluctant to answer or discuss because of a variety of factors, including ignorance, discomfort, or cultural norms. When parents do not provide the information and values, these are acquired from alternative sources, e.g. from teachers, peers, and the print and electronic media (Milton 2010).

Of late, the values and attitudes of young people towards sexuality are much related to their exposure to the electronic media i.e. television. Their sexual values are often being watched by society. Liberal sexual values, issues of gay, free sex, safe sex and what not, are often given space in local media industry. There is fear that this trend will permeate the lives of our young people in Malaysia. For now the sexual knowledge, values and attitudes young Malaysians stand on the average liberal pole. This means that there is a slight shift in their conservative traditional values that is much related to cultural beliefs and religion (Samsudin 2008). Many discussions of young Malaysians on sexual issues are prompted on sexual education and HIV/AIDS. Parents are not the main source of information on sexuality. They relate their discussions on their exposure to issues and images of sexuality through the cyber and peers.

Research by Samsudin (2008) revealed that young Malaysians aged above 16 possessed more liberal sexual values compared to the younger ones aged between13-16. Young Malaysians aged 13-15 states a mean score value of 4.2 , a much conservative sexual value compared to a mean score of 5.3 amongst the ones aged above 16 . This age group relatively shows a more liberal attitude towards sexual values. This research also revealed that sexual values have some connotations on the socio-economic family status of young Malaysians. There is a significant difference in the socio-economic status of youth from the perspective of sexual values. Young people from a high income family clearly show a high liberal value with a mean score of 5.3. It relative shows a significant difference with the lower socio-economic group family with a mean score of 4.8. This shows that sexual values shift from conservative in the lower income youths to a liberal value amongst young Malaysians that hail from high income family.

\section{Theoretical Framework}

Cultivation theory concentrates on one specific medium: television. It predicts not directs impacts on our thinking about specific issues or the attributes of those issues, but impacts on the very way one views the world ( Katherine Miller 2005). In cultivation theory, a comparison of the content of television and the beliefs people hold about the nature of the world is tested. Testing cultivation theory consists of two parts $i$. the determination of television content through content analysis and ii. Cultural indicators, where cultivation process involves assessing individuals' beliefs about what the world is like. Cultivation theory by George Gerbner presents the overarching proposal that television structures our beliefs about the world. It might be interesting to consider how the media shapes the views of the more intimate aspects of our lives. This theory befits this research as it tries to observe the extent the sexual images are able to influence young people's attitudes and values.

Among the most important characteristics of the observed event are the actions' consequences. It has been established that viewing televised violent behaviors lead to an increased viewer tendency to imitate the acts, due 
to a shift in attitudes toward the observed behavior. Humans learn in many ways and one of the most important alternative routes to learning is through watching others who are demonstrating behaviours. Researchers posited that if humans were motivated to learn a particular behavior, they would be able to learn by observing models. Learning can occur through the observation of these models. Viewing televised sexual images can also increase the tendency of the viewers to shift in attitudes toward the observed behavior.

The mediation process has given space and ideas for young people to form their own unique social reality constructs. It has become a crucial element to form an understanding on values and life style of young people. Many research have been done to prove that media has played a big role in the formation of young people' behavior. This is based on the views that continuous exposure to media has caused young people to form certain conceptions that media portrayals are true realities of the world. This is based on Gerbner's (1966) cultivation theory that predicts the impact on the very way we view the world. Through this theory, Gerbner (1966) proposes that television is able to cultivate our views of the world given its unique nature and the centrality of television viewing in our lives. The more one watches television, the more influence one gets on what is being portrayed because the notion of cultivation describes a long term and cumulative impact of television on our views of reality of the world Gerbner (1966)

Miller (2005) asserts that the nature of television is that it is a very unique medium. It is pervasive, highly accessible and coherent. It is highly pervasive in that almost every household can afford to own more than one television set. It is highly accessible regardless of language or time spent watching it. By just pressing the remote control, one can view any channel at any time of the day and viewers can be very selective. It is highly coherent because it presents the same basic messages about society across programming and across time. A viewer can even watch television without understanding the language nor not having the speaker on; be it right or not, message has already been relayed. Therefore, repeated intense exposure to 'false reality' of the media (television) leads to the perception of the 'reality' as normal which can influence the behaviour of young people. Gradually and through constant exposure, media (television) is able to penetrate into the social values of young people and slowly shaped their attitude and knowledge on sexuality.

Cultivation theory forwarded by George Gerbner (1966) is used in this research to see how young people perceive issues of sexuality as influenced by the television. It is of the opinion of the researcher that constant exposure to sexual images on television must have impacted the attitudes of young people and has somehow threatened their values towards issues of sexuality. Thus, the images that they see through constant viewing will serve to cultivate their views of the world. The link between the amount of television viewing and views of the world that are consonant with television reality, but at odds with the real world, forms the heart of cultivation theory (Miller 2005). It might be interesting to consider how the media shapes the views of the more intimate aspects of our lives. Do what young Malaysians see on television shape their very views of themselves? Do what they see on television shape their friendships and relationships? Do what they see on television, for example, sexual images, profane language or passionate kissing, can influence their values and attitudes towards sexuality? It might be interesting to consider how the media shapes the views of the more intimate aspects of their lives. It is obvious that this theory is able to find answers to the research objectives forwarded below.

\section{Research Objectives}

Globalization and the mediation age have exposed young people to various lifestyles in a wide and challenging environment. These challenges see no boundaries and this includes their personal lifestyle activities related to the issues of sexualities. Thus this study was an effort to examine the impact of portrayal of sexual images in the media and the mediation process of young people, focusing on television. The audience in general and young people especially are quick to accept images and messages portrayed on television as the truth when in actual what is portrayed is not all the truth. They are easily influenced by the images portrayed on television so much so the images become easily cultivated in their minds and behavior, whether it is positive or negative. Therefore, the objectives of this research are to:

i. To examine if the sexual images that young people watch on television influences their attitude towards sexuality.

ii. To examine the values the young people hold on to with regards to sexuality and television

iii. To examine how young people perceived issues and images of sexuality on television and how they try to reconcile with cultural norms and cultural expectations. 


\section{Research Methodology}

This particular current research reports findings from an analysis of images on sexuality in media channels (television) consumed by young people in Kuala Lumpur and Selangor. It examines how young people see or perceived what constitutes sexuality; how they are portrayed and represented, targeted at young people; how they perceived issues and images of sexuality and how they try to reconcile with cultural norms and societal expectations. Growing concern over teenage sexual behavior and lifestyle is apparent. This concern is, perhaps, not surprising given the increase in the abandoning of newborn babies among young people, rape cases and transmitted sexual diseases. Many studies have shown that the media has an important part to play in shaping the knowledge and attitudes of young people, and can influence discussion on values around sexuality. Thus, to establish the validity of these claims, this research attempts to ascertain if young people's belief and attitude towards sexuality are informed by the media, specifically the television, and to examine the values and attitude of young people towards sexuality as depicted in it.

All participants for this research were selected through purposive sampling to ensure there is an element of homogeneity. A total of 4 focus group discussions were conducted. Each focus group consists of five to six young people whose age are between 18-24, with a combination of two males and three females or three males and two females. 9 of the participants were working part-time while waiting for their Sijil Tinggi Pelajaran Malaysia (Higher School Certificate Examination) results while 12 of them were first and second year university or college students. The criteria of these participants were young people aged between 18-24 coming from a few areas in Kuala Lumpur and Selangor to get representatives from urban (Kepong and Bangsar) and sub-urban (Klang and Sabak Bernam) locations.

In order to understand young adult's lived experience with regards to growing up to the exposure of sexuality, we have to begin to explore and to map their identity. This is an important aspect of identity formation, including its relation to sexuality. All focus group discussions were recorded and later transcribed. The researcher will note exact quotes from the focus group discussions to be powerful evidence of the findings. Fieldwork was conducted for four weeks, taking one week for each group. Because Malaysia is a multi racial country, to ensure racial representation, a combination of three races minimum or more was considered. One group consists of Malays only, one group Chinese, one group Indians and one group a mix of Malay, Chinese and Indian. Thus only four groups or 21 participants were selected for this study to ensure a fair distribution of race among the participants.

\section{Results and Discussions}

In general, young people in Malaysia relied on mass media, especially the television, to get information on intimate human relations concerning sexual information as sexual education at schools was minimal, if any, to a certain extent in providing knowledge on sexual lifestyle. The first reaction to the topic of family communication about sexuality was to point out that young people do not 'discuss' with their parents about sexuality and as mentioned earlier they are not free to discuss matters pertaining to sexuality with parents as it is always thought to be a shameful subject. However, even if young people discuss about sexuality within family it would be between siblings. Issues of sexuality are observed in silence and young people learned more through friends and the media. Research results revealed that matters pertaining to sexuality are discussed with friends of the same sex.

A commonly mentioned source of sex information is peers and the media, specifically television and the internet. If adults are unwilling or unable to teach they will still learn, but they will learn from other sources. Most young people get messages about sexuality from friends or peers. The participants said they would discuss with friends or approach friends for advice on relationship and sometimes on sex. More serious matters will only be discussed with close friends who had been through similar experiences or someone who could really be trusted: discussing about sex with friends is like exposing a big secret of one's life. Different world views of expectation between parents and young people on sexuality make it difficult to find a common ground in communication. They thought that their ideas are different from those of their parents because they grew up in different environment and time frame. Most young people in Malaysia grew up in households where parents do not feel it is appropriate to show affection, even kissing and hugging. This creates an atmosphere where young people feel that intimacy is something that has to be hidden and be done in private.

Young people want to make their own decisions in expressing their sexuality. They should be aware that they cannot do that in a vacuum, absent from the influence of religion and traditional culture in contrast with the modern environment. However, they have the right to make their own choices with regards the issues of sexuality and the influence of media. But whatever decision they make should be made responsibly with deep thoughts about the future based on mutual respect and free from discrimination, coercion and violence. Within 
this framework, different cultural norms and traditions amidst the encroachment and invasion of global media can intermingle without conflict. Education on how to behave starts at home. Parents need to learn to talk to their children about sexuality and not just leave this to the media and their peers. Young people need ways to express themselves and make their voices heard and so gain access to information that is relevant and meaningful.

By and large, young people in Malaysia learn directly and indirectly about sexuality and sexual practice from the television. They learn directly if they choose to watch educational or religious programmes that talks on sexuality which poses positive connotation. They learn indirectly or unconsciously if they watch movies that have the portrayals on issues of sexuality such as kissing, necking and hugging, for example, with the opposite sex. At this particular fragile age, some young people are at the 'crossroads' of negotiating between culture and traditions, good and bad, and the old way instead of the new; restrictions that are holding them back which they feel not relevant today. They are confronted with critical and reverberating life choices that will shape their future avenues, facing conflict between two cultures and having a tough time making decisions. This is a pervasively influential time to start charting the right course for them so that their decisions will not be swayed by any forces. Some do know exactly what they want in life but some need guidance. What young people now need to do is to put a balance between the opposing forces: take the good things from tradition and combine them with the good things from modern culture.

This research results revealed that young people's view on the portrayal of sexual images on television influences their attitudes towards sexuality. They are aware that issues of sexuality are sensitive to be discussed openly in our society regardless of race, culture or religion. Media content, especially television, do play a crucial role in the identity formation, specifically the sexual knowledge, values and attitudes, of young people in the Malaysian context. Communication between generations about sexuality happens mostly through different styles of communication. Young people accepted that sexuality is a taboo subject; however clear messages were still transmitted. Majority of the participants do not experience significant conflict with parental expectations on sexual matters as they succumb to the societal norms that they are exposed to daily. By and large they shaped their behavior to meet parental expectations as well as attempting to pursue their paths to lead a normal life while adhering to cultural expectations which is by choice.

Based on this research, it can be said that young people who have a strong grip of life principle and integrity, a strong and moral foundation that starts at a very young age and a strict religious background will be wise enough to shake off all trials and tribulations. A normal and a harmonious family background and a formal and pleasant bringing up will help to shape, by their own behaviour and the decisions they make, changes in the society in which they and the next generation will live. This research holds strong evidence that the sexual images that young people watch on television influences their attitude towards sexuality. They carry values, attitudes and beliefs derived from their parents and from the society and culture in which they have been raised. The values that they hold have important implications for the future. This means that whatever decisions that they make, these young people are aware that they must reconcile with cultural norms and expectations, and also abide to religious thoughts and teachings.

\section{Conclusion}

The global media culture can be an independent force in the lives of young people, influencing behavioural and value patterns that differ from those of their elders. Some argue that information communication and technology carry a cultural package of values associated with Western culture. Facilitated by technology, media culture can sometimes conflict with more traditional concepts of how youth should behave. In urban centres, media culture and its predominant messages permeate almost all aspects of young people's lives. The culture "industry", referring to the entirety of the media and information technology, is a powerful tool through which young people can access information about almost anything. With such information, they can exercise their sexual and reproductive rights and make better-informed decisions about their lives.

The meanings that are gathered from media content do not have to be final but are open to interpretation and contemplation to suit an individual's personal needs. They use media and the cultural insights provided by them to see both who they might be and how they should behave. Culture, values and traditions are good if they are able to empower people to go forward and the opposite is true if it promotes downfall. Thus, Wietersheim (2005) says that it is important to teach children from a very early age to express their feelings, wishes and opinions. This encourages them to set positive goals for themselves, and helps them identify and understand different emotional outcomes with which to make their choices at decision-points along the way.

The mass media provide a wide-ranging source of cultural opinions and standards to young people. Young people would be able to look at these and decide which they found most favourable and also to what they would like to 
aspire to be, thus, gathering their knowledge, forming their personal values and shaping their attitudes towards issues of sexuality. It is timely that we rise to the challenge and ensure that our young people's understanding of sexuality is deeply grounded. Such dilemma should serve to alert us to the need for Malaysian conceptual frames for understanding sexuality and to motivate them to develop a more religious and culturally sensitive ways of engaging with sexual phenomena. This is a transition from childhood to adulthood while dealing with biological, psychological, spiritual and social challenges.

\section{References}

Bandura, A. (1977). Social LearningTheory. Retrieved from http://webspace.ship.edu/cgboer/bandura.html

Batchelor, S. (2001). Teenage sexuality in the media: much too young? In Burtney, E. and Duffy, M. (Eds), Young people and Sexual Health: Social, Political and Individual Contexts. Palgrave: London.

Botta, R. A. (1999). Television images and adolescent girls' body image disturbance. Journal of Communication, 49, 22-41. http://dx.doi.org/10.1111/j.1460-2466.1999.tb02791.x

Bragg, S., \& Buckingham, D. (2002). Young people and Sexual Content on Television: A Review of the Research. Broadcasting Standards Commission, London.

Brown, D., \& Bryant, J. (1990). Effects of television on family values and selected attitudes and behaviors. In J. Bryant (Ed.), Television and the American family (pp. 254-309). Hillsdale, NJ: Erlbaum.

Cantor, J., Bushman, B. J., Huesmann, L. R., Groebel, J., Malamuth, N. M., Impett, E. A., Donnerstein, E., \& Smith, S. (2001). Some hazards of television viewing: Fears, aggression, and sexual attitudes. In D.G. Singer, \& J. L. Singer (Eds.), Handbook of children and the media (pp. 207-307). Thousand Oaks, CA: Sage.

Chapin, J. R. (2000). Adolescent sex and mass media: A developmental approach. Adolescence, 35, $799-811$.

Cowan, G., \& Campbell, R. R. (1995). Rape causal attitudes among adolescents. The Journal of Sex Research, 32, 145-153. http://dx.doi.org/10.1080/00224499509551784

Cultivation theory of Mass Media. The Communication Initiative. The Analysis of Mass Mediated Public Message Systems. Retrieved from www.comminit.com/en/node/27072/307. Placed on the Communication Initiative site July 29, 2003. Last Updated July 292003.

Dacey, J., \& Maureen Kenny. (1997). Adolescent Development. Chicago: Brown and Benchmark.

Gerbner, G. (1995). Retrieved from http://www.aber.ac.uk/media/Documents/short/cultiv.html

Gerbner, G., \& Gross, L. (1976). Living with television: The violence profile. Journal of Communication, 26(2), 172-199. http://dx.doi.org/10.1111/j.1460-2466.1976.tb01397.x

Hamley, K. (1995). Media Use in Identity Construction. Retrieved from http://www.aber.ac.uk/media/Students/klh9802.html

Kelley, P., Buckingham, D., \& Davies, H. (1999). Talking dirty: Children, sexual knowledge and television. Childhood: A Global Journal of Child Research, 6, 221-242.

Kim Hak-Su. (2002). Youth in Malaysia: A Review of the Youth Situation and National Policies and Programmes. Economic and Social Commission for Asia and the Pacific (ESCAP). United Nations: New York.

Latiffah Pawanteh, \& Samsudin A. Rahim. (1999). Mediasation and emerging patterns of lifestyle among adolescents in. Malaysia. Retrieved from www.ippbm.gov.my/v2/index.php?option=com...view

Latiffah Pawanteh, \& Samsudin A. Rahim. (2009). Media Penetration and Cultural Identity Among Young people in Malaysia. Retrieved from www.eurojournals.com/ejss_11_2_05.pdf

Meschke, L. L., Bartholomae, S., \& Zentall, S. R. (2000). Adolescent sexuality and parent-adolescent processes: Promoting healthy teen choices. Family Relations, 49, 143-154. http://dx.doi.org/10.1111/j.1741-3729.2000.00143.x

Miller, K. (2005). Communication Theories: Perspectives, Processes and Contexts. Singapore: McGraw Hill.

Milton Lum. (2010). Learning about sex. The Star Online. Sunday, May $16^{\text {th }}$.

Nobaya Ahmad, \& Samsudin A. Rahim. (2008). World Programme of Action for Youth: A Malaysian Response. UPM: Selangor. 
Samsudin A. Rahim, \& Latiffah Pawanteh. (2003). The emerging generation. Media penetration and construction of identity among young people in Malaysia. In Samsudin A. Rahim (Ed), Kumpulan esei Isu-isu Komunikasi. Bangi: Pusat Pengajian Media dan Komunikasi.UKM.

Samsudin A. Rahim. (2005). Siri Prosiding. Realiti generasi muda: melangkah ke hadapan. Putrajaya: Institut Penyelidikan Pembangunan Belia Malaysia. Kementerian Belia dan Sukan Malaysia.

Samsudin A. Rahim. (2007). Generasi Belia: Satu cetusan pandangan. Putrajaya: Institut Penyelidikan Pembangunan Belia Malaysia. Kementerian Belia dan Sukan Malaysia.

Samsudin A. Rahim. (2008). Media dan generasi muda. Putrajaya: Institut Penyelidikan Pembangunan Belia Malaysia. Kementerian Belia dan Sukan Malaysia.

Shanti Balraj-Ambigapathy. (2000). An assessment of children's television programmes in Malaysia. In Anura Goonasekera (Ed.), Growing up with TV: Asian Children's Experience (pp. 157-212). Singapore; Asian Media Information and Communication Centre.

Stephens, S. (2007). Unheard Voices of Ethno_Racial Minority Youth: A Community-Based Research Project. Project funded by Canadian Heritage, Multiculturalism Programme: Sexuality Education Resource Centre.

Weiten, W. (2001). Psychology: Themes and variations (5th ed.). Stamford, CT: Wagsworth.

Wietershiem, E. V. (2005). Changing cultural norms and norms and values in the times of HIV \& AIDS. Sister Namibia. October, 24-25. Retrieved from http://en.wikipedia.org/wiki/Cultivation_theory

World Health Organization. (2007). Sexual and reproductive health of adolescents and youths in Malaysia. $A$ review of literature and Projects, (NLM Classification: WS 462). 